\title{
8 The Evolution of Indigenous Knowledge among Chamus - or Global Diffusion? ${ }^{1}$
}

The emphasis on tradition among the Maasai and Samburu obscures the extent of historical change. They portray their past essentially as a projection of their recent experiences and tend to assume that earlier communities were not radically different from the more remote communities of the present, apart from being more exposed to the uncertainties of intertribal warfare and shifting borders. The sequence of earlier age-sets provides an ideal scale for a chronology of major events. Yet even this is perceived less in terms of radical transitions than as a demonstration of the persistence of tradition. Between sporadic disasters, earlier generations are assumed to have experienced a similar lifestyle as their descendants, with similar opportunities for growth, and similar problems of survival. In contrast to this timeless perspective, the Chamus neighbours of the Samburu have a quite different view of their history, with oral traditions that associate radical changes in their social life with successive age-sets. Taking these traditions as an authentic reflection of their history, whatever the elaborations in matters of detail, one is presented with an evolutionary sequence that contrasts with the pastoralist view of chequered stability. To this extent, the Chamus have a sense of history as well as of tradition that goes back to their origins as foraging Dorobo.

\subsection{The Dorobo}

Small communities of hunter-gatherers were scattered throughout the pastoral region of East Africa, and they generally spoke the same language as their pastoral neighbours. In the Maa-speaking region, they were known as 'Dorobo'. Among the Kalenjin-speakers they were 'Okiek'; and among the Oromo-speakers, they were 'Warta'.

As foragers, the Dorobo exploited a different ecological niche from their Maa neighbours, whose herds ensured a more reliable and affluent lifestyle. By common consent, the dedicated commitment to pastoralism was vastly superior to the more hand-to-mouth nature of foraging. Maa pastoralists despised Dorobo for having no herds or wealth of their own. At the same time, their separate economies facilitated a

1 An earlier version of this chapter has been presented under the title 'Keeping Tradition in Good Repair: the evolution of indigenous knowledge and the dilemma of development among pastoralists', and published in Bicker, A., Sillitoe, P., and Pottier, J. (eds), 2004, Development and Local Knowledge. London: Routledge (pp. 202-217). I am grateful to Routledge for permission to draw on this article here. For fuller details on the Chamus see Spencer 1997: 129-203, 210-213; and on the Dorobo see Spencer 1973: 199-219. 
degree of casual trade, exchanging products of the bush and forest for sheep or goats (but not cattle). In times of severe drought and cattle epidemic, Maa pastoralists who had lost their herds might turn to the Dorobo as refugees and in effect become Dorobo until conditions improved and they rebuilt their herds. Conversely, ambitious Dorobo could hire themselves out as client herdsmen and even build up small herds of their own, joining the pastoralist community as stock owners. The boundary was open in both directions.

The sharing of a common language between foragers and pastoralists extended to their clothing, ornaments, social habits, and even their age-sets and clans, but only up to a point. The Dorobo camouflaged themselves at a relatively casual level in the eyes of the pastoralists, and it was this casualness that characterized them as Dorobo. Only by raising their standards could those that had settled among the pastoralists begin to surmount the stigma of being Dorobo. Another characteristic of Dorobo was their adaptation to a local ecological niche. This involved an intimate knowledge of their local terrain with changing seasons and shifting opportunities. Nomadic pastoralists responded to changing conditions quite differently. They had an intimate knowledge of the needs of their cattle, but as nomads who moved around as grazing conditions changed, they had an altogether shallower understanding of the ecosystem as compared with Dorobo. Another niche was the sensitive border between hostile pastoral tribes where the Dorobo could trade as middlemen. From time to time, the boundaries between rival pastoral tribes would shift, sometimes quite radically. This could mean that the Dorobo who were attached to a particular niche could find themselves surrounded by new pastoralist neighbours with different customs and a different language. They would then adapt to this situation, switching their language, clan and age-set affiliations, and adapting their superficial ornamentation to that of their new neighbours, while retaining their former niche and lifestyle as foragers. In effect, the changing political identities in the region were accommodated with least disruption to the Dorobo way of life as they built up new networks of interaction with their new neighbours, and would now be known as Okiek among the Kalenjinspeakers or as Warta among Oromo-speakers, and so on. To be Dorobo was to be Maa in language and a shadow of Maa in other ways.

\subsection{Chamus as a Quasi-oasis Society}

Lake Baringo is situated 50 miles north of the equator, covering an area of about 60 square miles, and fed by the seasonal run-off of rain water from the steep slopes of the Rift Valley in northern Kenya. Chamus oral traditions maintain that they were originally Dorobo who fished, hunted, and gathered edible plants and fruits of the bush in the vicinity of the lake. This was their niche. In their oral traditions, Parsaina clan were descendants of the original inhabitants. Parsaina were then joined by three waves of Kalenjin-speakers from the west, whose descendants are 
now known as Kabis, Kesieni, and Lamaee clans. However, there is no suggestion that Parsaina spoke any language other than Maa, which became the lingua franca for all Chamus.

The transition of Chamus from hunter-gathering to irrigation agriculture on the alluvial plain to the south of the lake is embodied in myth, portraying this as a chance event by serendipity. An elder of Kabis clan is said to have picked up a sprig of finger millet that had been dropped by a migrating bird. He decided to plant it, and then gathered the first crop. He gave seed to other Chamus and this new source of food spread among them. For this reason, Kabis clan played a leading role in rituals associated with their crops. This was so successful that it developed into an intricate system of irrigation. Because the migrating bird had been flying along the Perkerra river course that led from the ancestral home of Lamaee immigrants, it was elders of Lamaee clan who governed rituals associated with the irrigation system.

The earliest accounts of the Chamus were collected in the mid nineteenth century from Swahili ivory traders who returned to the coast after leading caravans inland. As they increasingly penetrated the Maasai area, they established a strategic provisioning centre among the Chamus to replenish their diminishing food supplies in return for products from the coast. The Chamus appear to have built up their irrigation system in response to the opportunity to trade. At this time, they lived in two congested villages (see Plate VI showing Chamus huts and granaries). Each village was surrounded by a double ring of thorn fencing. The larger village with 250 huts (Powell-Cotton) and an estimated population of 1,500-2,000 people (vonHohnel) was five miles south of Lake Baringo and situated on one of its estuaries (Perkerra or 'Great Uaso'). ${ }^{2}$ The smaller village was situated on another estuary and three miles further to the south. A few Chamus families also lived as a colony on an island in the middle of the lake, fishing, hunting and exchanging these foods for food grown by their mainland kin. From time to time, they would also keep goats, and the island served as a place of refuge for other Chamus in troubled times.

Joseph Thomson, the first European to visit the area, gave the following impressive account of the irrigation system in 1883 , noting that the Chamus

'have developed a wonderfully ingenious system of irrigation by artificial canals of (for them) great magnitude. They construct dams across the deep channel of the [Perkerra River] and this raises the level of the water to that of the plain, and then by an intricate network of channels, they spread the precious fluid over a large area, and raise their millet and melons.' ${ }^{3}$

2 Powell-Cotton 1904: 162; vonHohnel 1894:5. Powell-Cotton's is the most reliable indication of the size of the larger village, which combined with an estimate for inhabitants per hut among the Samburu in 1958 would suggest a population of around 1,100 inhabitants.

3 Thomson 1968: 264. 

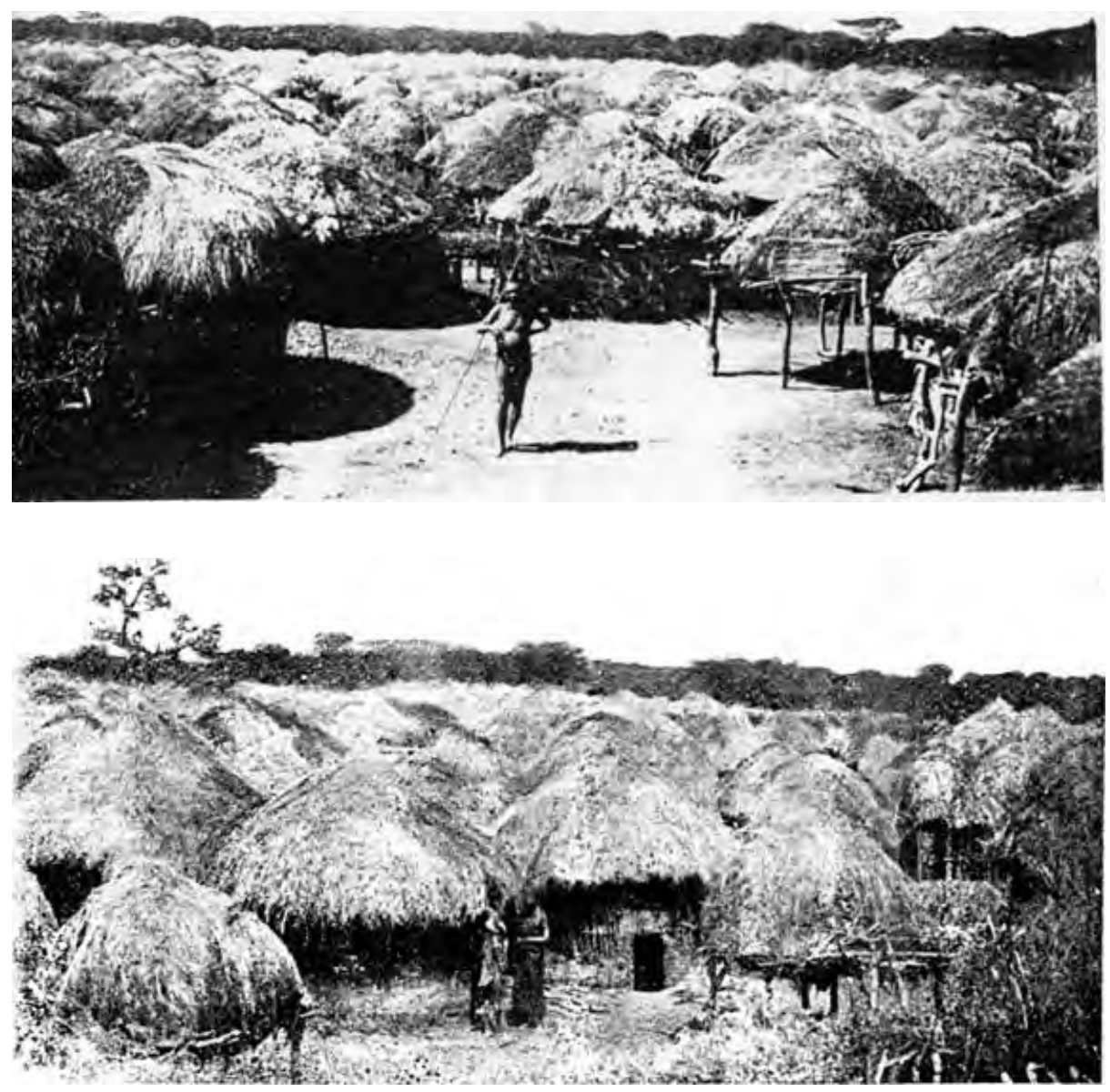

Plate VI: Two views of a Chamus village c. 1900 (from Johnston 1902: 812-3)

Irrigation systems generally are associated with highly centralized control, politically as well as practically, to coordinate and maintain access to water. Among the Chamus this was achieved through two levels. At the lower level, the system was divided into family-based plots under the strict authority of the male household head, who held the tenancy. His wives undertook all the routine tasks from digging and planting to harvesting and cooking, while the elder manipulated the watering of his plot and the distribution of the food, meting out the rations of grain for his family over the seasons. At the higher level was a Council of elders with ultimate powers over the operation of the total water system and over the tenancies of individual household heads. Each of these heads was both a member of the Council and accountable to it as a tenant. Decisions by the Council were binding on everyone. The ultimate sanction against a dissident tenant was to expel him from the village. 
The Chamus maintain that each of the successive transitions in their economy was considered in discussion by the Council. Successive age-sets are remembered for their contribution to this evolving process while they were active moran, but it was the Council of elders during these transitions that steered the process of decision making. There was a tacit acceptance of creeping change, but above all a premise that the wisdom of elderhood lay in pooling their experiences and insights in order to arrive at well considered courses of action. The wisdom of tradition in coping with the unexpected was seen to lie in this community of knowledge and discourse.

There was a downside to the Chamus economy, however. Thomson also noted that the area was infested by 'myriads' of rats that 'swarmed everywhere' and after inadequate rains to feed their system, the Chamus were obliged to eat the rats 'or any unclean thing'. The next three visitors to the area gave equally somber accounts, implying that the Chamus were struggling to survive. VonHohnel in 1888 noted that they:

'cultivate nothing but dhurra, eleusine, and gourds. The dhurra is an inferior, reddish brown variety, and of the gourds, we saw none for they had all been eaten up. Attempts had been made to cultivate maize brought by traders, but they were not successful. The loamy soil, which soon becomes perfectly hard again, even after heavy rain, makes agriculture very difficult, and there is generally a strong wind blowing in the afternoon, which raises clouds of dust. Large tracts of ground are divided, like a chess board, into plots three to four miles square [sic?], with a layer of soil only some few inches thick. Many of these plots were now lying fallow, and it is evident that the nature of the soil makes its cultivation extremely arduous, and that much care in arranging a rotation of crops is necessary. For irrigation, the natives make a number of artificial channels carrying off the water of the brooks, and in every way great toil produces only small results, even these often marred by depredations of the numerous birds. Now and then, too, elephants wreak havoc in the fields ...'

Visiting the area in 1890, Peters reported that the Chamus were 'suffering hunger' and the 'remarkable dryness' of the region 'often destroys the harvest and occasions famine.' In 1893, Gregory added. 'Last year [the Chamus] had no rain, and so the crops failed, and this year the rains had been so heavy that the crops had been washed away with the soil on which they grew'. ${ }^{4}$

From these remarks it seems probable during such times of hunger that Chamus foraging skills as ex-Dorobo would have been vital for their survival. Moreover, these skills may have been kept alive by previous famines of this kind throughout their period as irrigators. Yet while they experienced hand-to-mouth episodes associated with a Dorobo way of life, unlike Dorobo, the Chamus had developed a disciplined economy based on clear property rights. Moreover, unlike Dorobo, they did not attempt to merge with their pastoral neighbours, borrowing clan and age-set names

4 Thomson 1968: 264, 312; Von Hohnel 1894 (ii): 5; Peters 1891: 271; Gregory 1896: 118. 
or superficial practices. They had their own distinctive clans and age-sets with their own distinctive identities. The Chamus appear to have had peaceful relations with the Samburu over an indefinite period, but they were not Samburu.

In an overview of the evidence, David Anderson has stressed the heavy labour required to maintain the irrigation system and the problem of balancing this with the output of the system over the seasons and especially in years of drought. Immigrants were welcome as extra hands, but they had to be fed. Pastoralists whose herds had been decimated by drought could find a refuge among the Chamus, but the same drought also affected the irrigation system and failing crops. Then, as conditions improved and the ex-pastoralists rebuilt the nucleus of their herds, they would leave the Chamus, who still faced the problem of maintaining their system with a diminished work-force. Dams needed repair after heavy rains and annual replacement, and the furrows that filtered water from the river to the fields required heavy maintenance. Anderson suggests that the irrigation system had peaked in the 1870 s and was already in an irreversible decline by the time of Thomson's visit. As elephants became increasingly scarce, the price that Chamus demanded from traders for ivory became unrealistically high, and the coastal caravans meanwhile penetrated further inland where ivory was still plentiful and cheaper. ${ }^{5}$

The Chamus were clearly handicapped by the unpredictable extremes of their climate and by their primitive techniques and materials. While Anderson notes the shambolic nature of Chamus construction with badly built huts and flimsy dams made from boulders and brushwood, there are also impressive indications of their skills. He cites a visiting agricultural official in 1954 who noted that the Chamus women 'employ a simple system of box-terracing ... the accuracy of their bank construction was extraordinary, also their apparent ability to site the box-terraced lands so that an even flow of overflow water was received on the plots.' Again, elders had a means of preventing their wives from filching from their grain stores by colonizing spiders to spread their intricate webs over the entrances and memorizing the patterns of these webs until they decided to make the food available for their families. The Chamus also seem to have successfully saved their granaries from the 'myriad of rats everywhere'. 6

The sophistication of the irrigation system was apparently matched by the sophistication of the elders' Council in maintaining a control over this system and other activities that affected their society. A feature that may have played a major role in this fine balance was the ethos of Chamus society. Various writers have emphasised: that: the Chamus 'receive strangers kindly', whereas the Maasai were 'cruel and remorseless to the last degree' (New); that they were 'singularly honest and reliable' and their 'charming unsophisticated manners' contrasted with 'the ferocious and arrogant warriors of the Masai country' (Thomson); and that they were 'peaceable

5 Anderson 1988: 247-8, 251-2.

6 Anderson 1988: 247, 256, Thomson 1968: 263-4; Gregory 1896: 125. 
and friendly' and 'more modest than their insolent [Maasai] cousins on the plateaus who ... had developed a propensity for plunder and a thirst for blood' (Peters). ${ }^{7}$ In part, this appears to be a contrast between Chamus elders and Maasai moran and their different attitudes towards strangers in an era when the Maasai dominated the region. But it also surely reflects the stress on conformity among Chamus to maintain their erratic irrigation system as a collective enterprise, and reveals their elders as essentially diplomatic, which would have been an asset in their peaceful trading with outsiders and a necessary quality for influence in any meeting of the Council, where consensus and harmony were stressed.

If the elders were involved in overseeing their wives as dependent labourers and the irrigation system as a whole, then this raises the question, what contribution did unmarried youths and girls contribute to this unpredictable economy? According to Thomson: 'very little work being expected of the latter, and the sweetheart system being preserved. They all, however, occupy the same village.' But Thomson was describing the next stage of Chamus development when they were joined by Samburu who introduced an element of pastoralism into their economy, and he added: 'When parties go off on war-raids, they also contrive to eat a bullock by way of getting up their courage.' 8

This raises further questions. Before the arrival of Samburu immigrants, could Chamus youths - moran - have retained the hunting and fishing skills associated with their earlier traditions as Dorobo? Could this have provided a continuing lifeline for all Chamus when harvests failed? In providing an essential role for the moran, could this also have eased their induction into the collective economy?

\subsection{The Transition to Agro-pastoralism}

During its heyday, the Chamus irrigation system provided sufficient food to accommodate refugees from neighbouring peoples. These added to the workforce in return for hospitality and were absorbed into the existing four clans. Around 1870, there was an influx of destitute Maa pastoralists - the Toiyo - who had become detached from the main body of Samburu and had developed their own practices including river fishing skills while retaining their herds. When they migrated to join the Chamus, the Toiyo brought these skills with them and their commitment to pastoralism. As newcomers to the irrigation system, they are remembered for introducing river fishing to other Chamus, who had previously only fished in Lake Baringo. Their incorporation into the irrigation system extended to a recognized claim to ritual authority over the techniques of river-fishing, rather as the established Kabis

7 New 1873: 463, 469 based on early traders' reports; Thomson 1885: 234, 264; Peters 1891: $224,272$.

8 Thomson 1885: 264. 
and Lamaee clans held ritual control over crops and irrigation. As such, the Toiyo constituted a significant addition to Chamus society and formed a fifth clan.

The Toiyo immigrations were followed by further waves of destitute Samburu in the 1880s, and these formed five further clans, retaining their Samburu names and spear-heading the thrust to rebuild their herds through raiding, husbandry, and trading. It seems quite likely that vonHohnel was referring to Samburu immigrants when he wrote that the Chamus 'were very exacting about what they would take in exchange for their wares ... for ivory they must have cattle. ${ }^{9}$ A later source for building up Chamus cattle herds was as mercenaries who helped establish the incoming colonial administration against dissident Kalenjin and Turkana pastoralists.

The Samburu were the principal agents in the transition of the Chamus to agropastoralism, and they introduced their Chamus hosts - especially the young men to a growing element of pastoralism in their economy. A measure of the accretion of Samburu into an expanded Chamus society may be seen in the integration of their clan systems at this time. Altogether, the second wave of Samburu immigrants comprised representatives of five Samburu clans, of whom four formed a new ritual relationship with one of the four original Chamus clans. This relationship involved a reciprocal mixture of deep respect tempered in the final resort by privileged coercion. It was a practice borrowed from the Samburu and wholly absent among the Maasai, ensuring peaceful avoidances between previously hostile clans or sub-clans. This could well have appealed to the Chamus elders' Council as a means of integrating the newcomers peacefully and containing the aggressive edge associated with pastoral rivalries, smoothing the transition towards agro-pastoralism.

There were further immigrations by stragglers from the defeated Laikipiak Maasai from the east, who formed a further clan, and by Uasinkishu Maasai from the west who were absorbed individually by the existing clans. The tilt towards pastoralism also appears to have had some effect on the general ethos of Chamus society. The Chamus were previously regarded as peaceful irrigators, when close cooperation in maintaining their system under the control of the elders' Council had been essential. The pastoral side of their economy, both in terms of building up their herds by raiding and then in terms of defending these herds gave a stronger and more competitive role for younger men - the moran. Irrigation required coordination in order to realize ultimate self-interest and significantly this was in the hands of household heads as members of the elders' Council. Pastoralism, on the other hand, required dedication to the family herd within a much looser framework that could lead to a clash of interests. Some case examples involving immigrant Maa suggest a stronger element of aggressiveness associated with the pastoral culture and intense concern for their herds. This is to suggest a tilt towards initiative in the hands of younger men with

9 vonHohnel 1894: 5. 
short-term interests and away from the longer-term concerns of the elders' Council, who were struggling to maintain their irrigation system.

As they built up their herds by the first decade of the twentieth century, the Chamus consolidated the pastoral side of their economy by adopting the Maasai system of manyata villages to guard their growing herds. This was seen as a purely practical arrangement and, unlike Maasai manyat, there were no heavily ritualized overtones, but the separation of moran from the elders' villages and hence from their wives may be significant.

Beside the expansion of clanship, another indication of the integration between the irrigation and pastoral influences can be seen in terms of the Chamus age system, which contains a mixture of Samburu and Maasai elements, as well as other features that are distinctly different. It is tempting (though a matter of speculation) to strip away the Maasai features to reveal an earlier age system, and then to strip away the Samburu features to reveal a still earlier pre-pastoralist system. The significant point, however, is that the inclusive system was not an unstructured mishmash of elements borrowed at random. It was a system with its own rules and procedures that were neither Samburu nor Maasai, and it was integrated into a cycle that typically spanned 12 years, whereas the Samburu and Maasai cycles spanned 14 and 15 years respectively (Chapter 2 ).

In 1917, unusually heavy rains caused the Perkerra River to overflow, bursting its banks, altering its course, and leading to a flash flood that destroyed the irrigation system irreversibly. Two factors appear to have contributed to this.

First, official records suggest a sixfold increase in the cattle population between 1900 and 1920 (and this incidentally is identical to the increase in bridewealth over this period). Robert Chambers has attributed this increase to the reduction of intertribal raiding following the establishment of administration in the area. As a result, the high grass that had previously dominated the catchment area of the Perkerra River was grazed down and replaced by thick bush. This increased the run-off of surface water, eroding the banks of the river, and undermining the natural drainage that fed the irrigation system. ${ }^{10}$

A second cause of the flood is suggested by Anderson's analysis over a longer period, stemming from the time when the Chamus increased their irrigation production to meet the growing opportunities for trading, even before Thomson's visit in 1883. The system then became overworked, steadily eroding the soil cover until it finally succumbed to the flooding. In other words, the Chamus had overexploited their irrigation system in addition to over-grazing the area that supplied its water. Whatever the balance between these two explanations, the Chamus became increasingly reliant on their newly acquired stock, and pastoralism now became the most successful component of their mixed economy.

10 Chambers 1973: 345-6 
Following the flood, individual families dispersed and started to create small scale irrigation works at suitable spots around the lake. These met with irregular success and inferior unmarketable crops, alternating with reliance on famine relief. Six years after the flood, the two villages were reported to be practically deserted, except for a few older families. The elders' Council survived and, according to Anderson in 1980, it 'still functions dealing with controls over grazing as well as irrigation', although with a growing and scattered population, it seems almost certain that its powers and procedures would have modified since the flood. ${ }^{11}$

\title{
8.4 The Transition to Individualism
}

\begin{abstract}
'The first man who, having fenced in a piece of land, said "This is mine," and found people naïve enough to believe him, that man was the true founder of civil society. From how many crimes, wars, and murders, from how many horrors and misfortunes might not any one have saved mankind, by pulling up the stakes, or filling up the ditch, and crying to his fellows: Beware of listening to this impostor; you are undone if you once forget that the fruits of the earth belong to us all, and the earth itself to nobody.'
\end{abstract}

Jean-Jacques Rousseau, Discourse on the Origin of Inequality, 1754

In pre-colonial times, polygyny was possible among Chamus, but elders preferred monogamy, which avoided all the troubles associated with younger wives and competition for and between wives. On the other hand the Samburu and Maasai pastoralists had a different attitude towards property and preferred polygyny as a means towards accommodating growing herds. This implied later marriage for young men and earlier marriage for girls (Figure 2.1), and the Samburu age-set system especially was geared towards this end (Table 2.2), whereas Chamus age-set system only produced a surplus of marriageable girls up to a point.

While the irrigation system faltered, the human population and the herds continued to multiply, and the cattle were grazed further and further afield during dry seasons. Challenges to the age-set system became a gauge of a growing transition towards a more individualistic society. An early indication of this was the attempt to evade a rule that tied the initiation of boys to the inauguration of a new age-set: if a boy missed this, then he had to wait twelve years for his next chance. With increasing numbers of cattle, more monogamous elders with small families were holding back the initiation of their sons to retain their use as herdboys, delaying their initiation and ultimately their marriages and marriage prospects. Some 'boys' were even said 
to have grey hairs by the time they could marry. ${ }^{12} \mathrm{~A}$ few youths of Kiliako age-set who had missed the inauguration ceremony around 1901 absconded to become unofficially circumcised by a willing expert from outside Chamus, and then they claimed the right to 'climb up' to Kiliako. This initiative was followed by a trickle of members of the next three age-sets until the elders successfully threatened to curse any boys who attempted to climb up to Merisho age-set (initiated in 1948). The numbers were insignificant, but they revealed a readiness to challenge the system from below and a belated determination to maintain it from above.

Meanwhile, attempts to enter the growing market economy by reinstating the principal irrigation system failed, and this increased the pressure on the young men of families without stock to find casual wage employment outside the Chamus area. Over successive age-sets, this increased the autonomy of these young men and their independence as elders when they returned to their Chamus homes. Exposure to the cash economy was now undermining the age-set system, which was seen as regressive in an era that encouraged peaceful competitiveness. The manyat were increasingly regarded as superfluous by fathers who felt they had lost control over their moran sons. In line with an increasing awareness of national trends, there was a rapid increase in the demand for schooling beyond the primary level, clashing with traditional notions of the role of moranhood. There was increasing pressure for lowering the age of circumcision. Elders increasingly ignored the age-set restrictions on early marriage for their sons.

These trends were set by those who were able to take advantage of new opportunities. But they were just one side of the increasing differentiation within Chamus society. On the other side were those who had stayed at home to tend the family herd or what remained of the faltering irrigation economy, who had no schooling, and could not afford to release their sons for schooling or early circumcision or marriage. Significantly, the polygyny rate among the Chamus by 1980 was almost identical to that of the Samburu in 1960 (1.5 wives/elder), but whereas the Samburu data showed a distinct association with age (Table 2.1), this is less pronounced among the Chamus suggesting a more general distinction between rich polygynists and poor monogamists whatever their ages. ${ }^{13}$

The increasing polarization of Chamus society is highlighted by Peter Little's rigorous research in 1980. This followed the privatization of land by the Kenya Government after Independence in 1963, and coincided with the growing wage

12 The Samburu evaded this problem by dividing their age-sets into three or four initiation periods, and the Maasai by dividing it into two (right and left) and permitting some late initiations. This appears to be the reason why the Chamus have a shorter age-set cycle (of c. 12 years) than the Samburu or Maasai: there was more pressure on Chamus elders to allow early initiations for fully grown youth, and hence a briefer cycle between initiations).

13 Little (personal communication); Spencer 1997: 87-8, 178. 
economy and the emergence of new elites. Among the Chamus, enterprising younger men had taken up new opportunities of wage employment, and they could now reinvest their savings in the mixed agro-pastoral economy. This was at the expense of the less enterprising families, who now became increasingly marginalized.

In this process, the need to employ casual labour rose during the critical season before planting, inflating wages at this time. This attracted poorer farmers, in spite of the fact that they could not at the same time plant their own crops and tend their own herds. By yielding to the short-term gains of high wages, they and their families were drawn into a downward spiral, especially during the hungry season. Eventually, in order to survive, they would sell off their herds and their newly acquired rights to land, and ultimately become badly paid full-time labourers, even on the land that they had previously owned. Conversely, those that had built up some capital could afford to pay the higher wages during the critical period, hire tractors, and buy the land and herds cheaply from the impoverished, increasing their capital in the long-term. With increasing yields, they could offer grain instead of wages to their employees and expand their holdings further. As competition for farmland increased, the successful owners would fence off their land to establish exclusive ownership and secure the best dry-season pasture for their herds, again at the expense of poorer herdsmen, whose free-range pastures were increasingly relegated to waterless tracts. Feeding on their profits enabled the successful to take on further wives and to give their children extended schooling, anticipating the possibility of more highly paid opportunities in work and diversifying the household economy still further in the next generation. In this way, social differentiation according to age in the traditional economy was being almost completely replaced by a new form of differentiation based on individual success in a capitalist economy. The earlier communal enterprise was now fragmented into a free-for-all - among the wealthy. ${ }^{14}$

\subsection{The Growth of Knowledge}

The successive transitions experienced by the Chamus from foraging to the development of private property may be viewed as a microcosm of social evolution in terms of the growth of knowledge. This has a bearing on the birth of anthropology as a discipline, when unveiling the macro-history of civilization became entangled with the prevailing concept of evolution. This concept concerned two quite separate streams of dispute: social evolution on the one hand and biological evolution on the other. Their separateness involved wholly different time scales. Homo sapiens was fully established as a forager long before the appearance of nomadic pastoralism with domesticated herds or the invention of agriculture with settled communities.

14 Little 1992: chapters 4, 5, 7. 
The question of 'social evolution' hinged on the balance between original invention and the diffusion of inventive ideas across the globe. Increasingly, it was the concept of diffusion that held sway. This was illustrated for the Maasai, for instance, when Merker's (1904) study became caught up with the German school of catholic diffusionists (Kulturkreise), who sought to link the dispersal of humanity with the early chapters of the Bible, and hence the Maasai with a lost tribe of Israel. The only lingering interest in evolutionism concerned parallel stages of historical development between earlier civilizations of the New World when compared with the Old, since these could not be simply explained by diffusion. This ultimately boiled down to an archaeological quest to identify similar but independent sequences of invention and development between the two major regions. To the extent that these pointed in the same direction, they suggested implicit laws of social evolution, as against the uniqueness of each new invention prior to its diffusion. By the time that Malinowski gave social anthropology a kick-start in the 1920s, evolutionism only survived in this archaeological quest, and he saw his principal rival as the sterile debate among diffusionists seeking to unravel history from indirect evidence as against his own emphasis on interpretation through extended anthropological involvement with living societies. ${ }^{15}$

In reconstructing Chamus history, however, the debate between evolutionists and diffusionists is not altogether sterile. At a trivial level, one may consider the oral tradition that their cultivation of crops arose out of the arbitrary decision by an elder of Kabis clan to plant a sprig dropped by a migrating bird, whence the claim to have discovered agriculture as an independent invention. The more likely alternative is to suggest that planting crops (and indeed the techniques of irrigation) had been invented elsewhere, and spread to the Chamus by the diffusion of knowledge. The oral account is hardly credible, but it is also trivial in the sense that it is impossible to substantiate either way: independent invention or the diffusion of technology - and from where? Except for this one incident, the oral traditions of Chamus development appear to be credibly supported by the evidence of early travellers, and with no suggestion of other independent inventions. ${ }^{16}$

At a less trivial level, one may ask whether the whole pattern of Chamus development, from their foraging ancestry to the emergence of individualism, followed some sort of evolutionary pattern, whatever the outside influences. As E.B. Tylor pointed out, once a novel feature has been adopted by a whole society, it is

15 Harris 1969, 379, 634-53.

16 Chamus oral traditions do not appear to touch on the origin of their irrigation system and this could have been invented locally. But there were also a number of other irrigation societies on the fringes of the Maa area, and the technology could have been borrowed by the Chamus from any of these (Spear 1993: 131-2). More to the point, the Chamus would have had to develop their technology in response to the local topographical and ecological conditions which could not be borrowed. 
irrelevant whether it was invented independently by one member or borrowed from elsewhere. ${ }^{17}$ Either scenario would involve a process of diffusion from its source and indicates that the society was ready to adopt it. This is born out by the sheer number of scientific inventions and discoveries that have been made independently by two (or more) pioneers at about the same time. ${ }^{18}$

This is quite close to Karl Popper's view of Objective Knowledge, although I would prefer to label it 'potential knowledge'. ${ }^{19}$ In this model, human awareness and endeavour focus on the problems of existence as they occur, and these are resolved through trial and the elimination of error. Selective pressures weed out ideas and experiments that do not stand the test of reality. They either succeed and become incorporated into normal practice in a process of adaptation, or they fail and will be discarded or ignored. As a result, routine patterns of understanding build up through the experience of successful and failed attempts; and where a pattern establishes itself as an underlying working premise then this provides a basic understanding: a strategy that suffices until it too is put to the test. The process of revelation and criticism is without end. The fate of a novel idea, like a mutation, depends on success or failure. If it succeeds, it spreads and becomes incorporated into the body of collective knowledge, and as Tylor noted, it may be a moot point whether this was an original or a borrowed idea. The significant point is that the community is ready to adopt it.

In Popper's model, Objective Knowledge consists of the sum total of the subjective knowledge of individuals, beliefs, interpretations, and understandings. No single person has more than a partial grasp of this knowledge, but collectively it is within their grasp: it is 'potential knowledge'. This provides an autonomous world of possibilities that lie beyond the awareness of any single knower. It provides a matrix of ideas from which the next invention or discovery will emerge when a particular combination of pieces of information are brought together to solve a problem. This can only be achieved through the interaction of individuals sharing their subjective experiences, bringing a variety of points of view until a novel and relevant combination of ideas emerges and becomes established.

Popper regarded this process of acquiring wisdom through trial and the elimination of error as the social equivalent of Darwin's notion of adaptation by natural selection in biology, albeit at a vastly accelerated pace. The same model is applied, but it concerns shifts in human culture - in knowledge that informs a way of life - rather than the evolution of a living population as a species, a natural selection of hunches rather than of mutant offspring. The resolution of problems is

17 Tylor 1865: 378-9, cited by Harris `969: 175.

18 Ogburn and Thomas 1975: 61-77. This article lists 148 simultaneous inventions, including, of course, Darwin and Wallace on the principle of natural selection in 1858.

19 Popper 1972, especially chapters 4 and 7. 
achieved through creative social discourse rather than procreative sexual intercourse: the stuff of history rather than of genetic evolution. The accumulated experience, imagination, and partial knowledge of individuals combine to form a cultural pool of awareness that corresponds to a gene pool in the biological model, where each organism contains only a partial combination of the possible genetic information. The coming together of minds on a particular problem selects from the potential body of knowledge, providing a fertile breeding ground for new combinations; and out of this experience, new propositions are thrown up that undergo a critical process of appraisal until one is favoured and put to the test.

The model can be elaborated with regard to the underlying premises that structure the syntax of knowledge and provide strategies for interpretation and action. When there is a shift in circumstance, this creates a problem whose resolution may hinge on the community's ability to engage in a self-critical dialogue that breaks through the shell of their basic doctrines. Various imaginative 'mutant' forms may enter the mainstream of awareness, rewrapping the old package to form a new one: a Kuhnian paradigm shift. In Popper's scheme, it is not society as a biological entity or species that is threatened with extinction by changing circumstances, so much as rigidly held cultural premises.

Applying this model to the successive transitions of Chamus society, these were bound up with a continuing dialogue that was hammered out in their elders' Council and arose out of problems whose resolution lay beyond the knowledge or experience of any one elder. The wisdom of tradition was seen to lie in this community of discourse and the readiness to share insights and recognise opportunities in a process of revelation as ideas jostled for attention in a search for agreement.

An elaboration of Popper's model would allow for the fact that the Objective Knowledge of the elders would have been circumscribed by the fact that women were excluded from the elders' Council. To the extent that gathering edible products of the bush and other domestic activities were solely undertaken by women, they would have their own Objective Knowledge. They would share this collective wisdom in their own specialized interaction, and their accumulation of understanding would be different from that of the elders' Council. Similarly, to the extent that youths (and not elders) were aware of the current opportunities for hunting, these would be part of their Objective Knowledge. Again, before Samburu refugees were adopted into the Chamus irrigation community, they too would have their specialized collective wisdom derived from the care of their herds. This would have been incorporated into the collective wisdom of the Chamus Council only when Samburu immigrants were admitted to its deliberations. In other words, Objective Knowledge is relative, and in a society where there is a strict division of labour, the world of Objective Knowledge is similarly divided. In Popper's terms, each division constitutes a Closed Society.

In this model, the growth of knowledge is perceived as a deliberate attempt to resolve a series of problems. To the extent that there is an element of purpose in this process of selection, it has parallels with a Lamarckian view of evolution. The 
'evolution' of knowledge is speeded up precisely because it does not rely on random suggestions, but on informed guesses that are oriented towards a resolution in the first place. Nevertheless, to the extent that there is an element of random chance in the learning process of individuals that precedes an ability to understand problems or to have hunches that address them, this suggests a more Darwinian process that has neither purpose nor a presumption of progress. Such a pattern may build up in early life - from the random experimentation of infants, as they adjust to a strange world, to the more directed play and increasing rapport among children. In other words, a Lamarckian pattern of social behaviour among elders may be the outcome of a more Darwinian experience among individuals struggling with their youth.

Putting to one side the Lamarckian implications of this model and apparently quite independently of Popper's work, an elaboration has been proposed by Warwick Bray, providing an archaeologists approach to social development. This incorporates a series of parallels with the taxonomy of Darwinian evolution that takes the argument to a further stage. ${ }^{20}$ Bray's list of evolutionary processes can be illustrated by the sequence of changes among the Chamus that do not suggest a purposeful evolution but the unplanned drift of their history all the way from foraging to the emergence of individualism and private property. This taxonomy and summary of Chamus oral history is presented in Chart 8.1.

To the extent that a Darwinian model appears wholly appropriate, the growing pains of anthropology as an argument between evolutionists and diffusionists now appears to have missed the point. By shifting Darwin's basic model from its biological origins to the notion of the evolution of ideas through social intercourse, Popper's model fits rather well. Diffusion is an aspect of the evolution of ideas, whatever their origins, and this ultimately leads towards a convergence of global problems as the ultimate challenge.

\subsection{Conclusion: Keeping Tradition in Good Repair}

Chamus oral traditions of the role and effectiveness of their elders' Council reflect the aspirations of elderhood among the Maa generally. However the Chamus lived in two compact villages and their complex irrigation system made it necessary to maintain a collective discipline in the distribution of water and keeping this system under constant repair. Whereas the livelihood of Maa pastoralists was based on their herds which were owned and managed independently by family heads, and this encouraged dispersal to make best use of the grazing. They were scattered in small semi-mobile settlements over a significant area of East Africa. The closest that the Maasai came

20 Bray 1973. Another independent invention? Bray's article makes no mention of Popper's earlier work, and it was apparently conceived quite independently (personal communication around 1990). 
Chart 8.1: Episodes in Chamus oral history compared with evolutionary processes

Dorobo ancestors of Chamus knew their local ecological niche $=$ Specialization intimately just as Maa pastoralists knew their's

The transition from foraging to agriculture occurred when an

$=$ Successful mutation elder by chance planted a sprig of millet $\&$ collected his first crop

He gave seed to other Chamus and this spread as a new source of food

The Chamus then developed an intricate system of familybased irrigation which was controlled by a Council of elders

The food surplus enabled them to accommodate impoverished refugees from neighbouring peoples

These included the Toiyo, a splinter group of Samburu who

$=$ Adaptive radiation*

$=$ Stabilization

$=$ Adoption

$=$ Genetic drift* had developed their own technique of fishing on Lake Turkana And also traders who exchanged manufactured goods for food As the pastoralist immigrants recovered their herds, Chamus became a mixed agro-pastoral economy

Some youths illicitly 'climbed' to become moran prematurely until they were threatened with their firestick patrons' curse

With increasing opportunity to trade, the irrigation system expanded, became overworked and was destroyed by a flash flood

Pastoralism then became the major component of their economy

However, the creeping intrusion of capitalism undermined the traditional system in the less remote and more fertile areas

This created inequality and an unbridgeable gulf between traditionalists and innovators, and between old and young

Chamus entrepreneurs built up land-holdings and started fencing these off, undermining the communal traditions of ownership

And as they increasingly exploited the poor, so the traditional $=$ Extinction culture of Chamus society was poised to disintegrate
$=$ Symbiosis

$=$ Hybridization \& polymorphism

$=$ Unsuccessful mutation

$=$ Over-specialization

$=$ Selective adaptation

$=$ Anagenesis*

$=$ Cladogenesis*

$=$ Breakthrough

* Adaptive radiation: successful diffusion from a single source. Genetic drift: an isolated colony develops different traits from its parent population Anagenesis: creeping divergence over a wide area leads to a continuum of variation Cladogenesis: substantial divergence across some boundary leads to separate species 
to achieving the ideal of unity was through local interaction within each age-set of each tribal section, where consensus was paramount at their meetings. This had its roots in the manyata experience of moran, where democratic decision-making was mandatory as the ultimate preparation for elderhood. This ideal was compromised among the Samburu by loyalties to the clan, which cut across age-set loyalties, but within each clan there was still a spirit of age-set unity.

Unlike the Chamus, the Maasai and Samburu had no oral traditions of progression from earlier forms of society. Historically, they interacted with agricultural and Dorobo neighbours and even dispersed to live among them in hard times, but these migrations were remembered as temporary expedients rather than as significant steps in their development. ${ }^{21}$ There was no suggestion of evolutionary stages as portrayed for the Chamus in Chart 8.1.

Yet, the taxonomy listed in this chart could apply in other ways. Popper's model focuses on the development of knowledge though social interaction shaped by a process of natural selection. A variety of other processes involving social interaction seem relevant to an extension of this model, such as shifts in popular religion or the spread and decline of fashion motivated by the pull of popular culture, or indeed other products of interaction that are independent of practical knowledge (cf. Bateson's distinction between eidos and ethos). At the risk of overstretching the argument, consider the following synopsis of the chapters in this volume.

Chapter 1 . The distortion of history through successive elaborations of reminiscences may be viewed as a process of repeated mutation and natural selection, and the spasmodic switch in fashionable paradigms in (eg.) anthropology follows a similar course (and are often perceived as breakthroughs in understanding).

Chapter 2. The exploitation by elders of physically stronger moran and of physically weaker women may be viewed as a form of parasitism. Also, the contrast in the profile of age relations between northern and southern Maasai, and the balance between these profiles displayed among the intermediate tribal sections may be regarded as polymorphism. And they could even suggest anagenisis, raising new questions concerning the genesis of this broad continuum.

Chapter 3. Stratification by age suggests cladogenesis indicating clear boundaries between age-sets, overriding the tendency towards mutation and natural selection that challenge these boundaries and the age system itself.

21 Berntsen 1979, Waller 1985. 
Chapter 4. Age-set exogamy is linked to excessive group indulgence within each age-set and leads to a symbiotic relationship between rival age-sets in the quest for wives.

Chapter 5. Innovations in song \& dance by each new age-set of moran (and indeed at every performance), may be viewed as successful mutations that result from the rapport established in the interaction of dancers. Where an attempt to generate a dancing event fails, then natural selection has taken its toll.

Chapter 6. The generation of anxiety through ritual leading to increased suggestibility may be viewed a preadaptation prior to a radical change in relationships.

Chapter 7. The transformation of religion among Samburu converts may be viewed in terms of genetic drift, or perhaps as cladogenesis if this develops into a clear rift between traditionalists and transfigurationalists, or even to the extinction of one or the other through cumulative forces of natural selection.

Chapter 8. The role the Chamus elders' Council has an affinity with a Lamarckian view of evolution as a purpose-led process. ${ }^{22}$ However, the prior experience of individuals as children, learning from random experimentation, has a more Darwinian flavour, leading to a sense of purpose in approaching problems. Similarly, unplanned events that precipitated substantial shifts in the pattern of Chamus existence parallel a Darwinian view that has neither purpose nor a presumption of progress. Either way, change normally takes place through a series of small responses that are constantly subject to forces of natural selection.

Chapter 9. The skill in elders' oratory and respect for their knowledge and understanding may be viewed as specialization: a process that is subject to natural selection. The heated exchanges during their debating may reflect adjusting to changes that are already taking place, as different points of view, like mutations, battle for survival in a challenging environment.

Most of these themes suggest a persistence of status quo rather than any growth of knowledge, but they each are the product of interaction between Maa where natural selection plays a significant role. The development of the Chamus towards individualism and a polarization between rich and poor does represent a transition that can be perceived in evolutionary terms, and this is also reflected in more recent studies of the Maasai, Samburu and other Maa-speaking peoples. Tradition appears to have lingered in the remoter areas, but it is always subject to modification. Within

22 Popper 1972: 268-280, 1973. 
their traditional areas, moran cling to the modified ideals of moranhood, while successive age-sets of firestick patrons revere clouded memories of the past and still cling to their traditional role. Nevertheless, these elders recognise the need to reinvent details of ritual practice with changing times, as they always have done. Maa-speaking societies and their traditions have been and are involved in their contemporary times. The mechanism for this is through casual interaction and ad hoc gossip, building up to collective meetings when they strive to reach a consensus on major issues. Similarly, the Chamus elders' Council were involved in the 'present' at each stage, periodically adjusting their traditions to keep them in good repair, just as they sought to maintain their failing irrigation system. The significance of tradition is not its inflexibility, but its emphasis on the continuity of society itself. 